\title{
REDUCING VIBRATIONS OF ELECTRIC CENTRIFUGAL SUBMERSIBLE PUMP THROUGH INSTALLATION OF THE DYNAMIC DAMPER
}

\author{
• • бдр химов, · • леев, • • икбул тов , • • б нов, \\ хриев \\ M. V. Gabdrakhimov, A. S. Galeev, G. I. Bikbulatova, S. L. Sabanov, K. R. Fakhrieva
}

фимский госуд рственный нефтяной технический университет, фили л, г. ктябрьский льметьевский госуд рственный нефтяной институт, г. льметьевск

лючевые слов : демпфирующее устройство; жесткость демпфирующего устройств ; смещения уст новки; скорость р спростр нения продольных колеб ний в колонне

Key words: damper; rigidity of damping device; unit offset; velocity of propagation of longitudinal vibrations in the string

лектроцентробежный н сос в сост ве

подвешив ется н колонне н соснокомпрессорных труб н глубине несколько сотен метров. процессе эксплу т ции уст новок довольно ч сто возник ют интенсивные колеб ния компоновки, приводящие к «полету». озбужд ющими колеб ния сил ми являются силы инерции неур вновешенных м сс [1]. редл г ется уст новить под хвостовик при помощи демпфер для перенос вибр ции с $\quad$ н хвостовик. д нной ст тье выполнен р счет п р метров вибр ции компоновки в з висимости от п р метров демпфирующего устройств .

счетн я схем компоновки приведен н рис. 1, где нижний конец колонны н сосно-компрессорных труб жестко связ н с м ссы $m_{2}()$; рующее устройство соединен с грузом (хвостовик) м ссы $m_{1} ;$ н уст новку действует г рмоническ я сил $P \cos \omega t$, где $P-$ мплитуд силы, $\omega-$ углов я ч стот переменной силы, $\omega>0$.

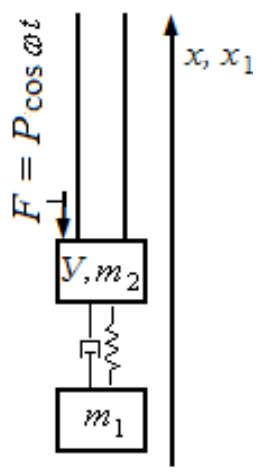

ис. 1. счетн я схем компоновки с хвостовиком 
р метры демпфирующего устройств обозн чим $\lambda-$ жесткость демпфирующего устройств и $\mu$ - коэффициент, х р ктеризующий демпфирующие свойств демпфер .

ыясним, к кими должны быть п р метры $\lambda, \mu$, чтобы при уст новившихся коле$б$ ниях колонны уст новк ост в л сь в покое.

ля удобств исследов ния силу $P \cos \omega t$ предст вим в комплексной форме $P e^{i \omega t}$, вещественн я ч сть которой р вн $P \cos \omega t$.

з условия ( ) следует, что смещения уст новки м ссы $m_{2}$ совп д ют со смещениями нижнего конц колонны, то есть р вны $u(0, t)$.

оэтому колеб ния всей системы будут описыв ться ур внениями

$$
\left\{\begin{array}{l}
u_{t t}+b u_{t}-a^{2} u_{x x}=0, \\
m_{1} \ddot{x}_{1}=-\lambda\left[x_{1}-u(0, t)\right]-\mu\left[\dot{x}_{1}-\dot{u}(0, t)\right], \\
m_{2} \ddot{u}(0, t)=E S u_{x}(0, t)-P e^{i \omega t}-\lambda\left[u(0, t)-x_{1}\right]-\mu\left[\dot{u}(0, t)-\dot{x}_{1}\right]
\end{array}\right.
$$

и гр ничным условием

$$
u(\infty, t)=0
$$

без н ч льных условий, т к к к р ссм трив ется уст новившееся движение. этих ур внениях $b$ - коэффициент, х р ктеризующий вязкое трение колонны об окруж ющую среду; $a$ - скорость р спростр нения продольных колеб ний в колонне; $m-$ м сс уст новки; $E$ - модуль нг м тери л колонны; $S$ - площ дь поперечного сечения колонны; $x_{1}=x_{1}(t)-$ смещение груз ; $u=u(x, t)-$ продольное смещение поперечного сечения $x$ колонны в момент времени $t$.

висимость $u$ от $x$ и $t$ будем иск ть в виде

$$
u=A e^{-k x+i \omega t}+B e^{k x+i \omega t},
$$

где $A, B, k$ - конст нты, подлеж щие определению. одст новк выр жения (3) в первое ур внение системы (1) д ет кв др тное ур внение относительно $k$ :

6 его корня

$$
a^{2} k^{2}+\omega^{2}-i \omega b=0
$$

$$
k_{0,1}= \pm \sqrt{\frac{i \omega b-\omega^{2}}{a^{2}}}
$$

предст вим в пок з тельной форме

$$
k_{0}=r e^{i \phi}, k_{1}=r e^{i(\phi+\pi)} .
$$

$$
\text { огд } \quad r=\frac{1}{a} \sqrt[4]{\omega^{2}\left(\omega^{2}+b^{2}\right)}, \phi=\frac{\pi}{2}-\frac{1}{2} \operatorname{arctg} \frac{b}{\omega}, \text { где } \phi \in\left[\frac{\pi}{4}, \frac{\pi}{2}\right] \text {. }
$$

тсюд получим величины

$$
H=r \cos \phi=\frac{1}{\sqrt{2} a} \sqrt{\omega\left(\sqrt{\omega^{2}+b^{2}}-\omega\right)}, \quad G=r \sin \phi=\frac{1}{\sqrt{2} a} \sqrt{\omega\left(\sqrt{\omega^{2}+b^{2}}+\omega\right)},
$$

идим, что

$$
\left\{\begin{array}{l}
H \geq 0 \\
G>0 .
\end{array}\right.
$$

венство $H=0$ возможно лишь при $b=0$. 
ыр жения (4) предл г ют н м две р вносильные возможности выбор зн чения $k$. них $\operatorname{Re}\left(k_{0}\right)=r \cos \phi \geq 0, \operatorname{Re}\left(k_{1}\right)=r \cos (\phi+\pi) \leq 0$. ля определенности выберем $k=k_{0}$. этом случ е

$$
k=r(\cos \varphi+i \sin \varphi)=H+i G
$$

редположим, что в (3) $B \neq 0$. огд при $x \rightarrow \infty$ будем иметь $\left|A e^{-k x+i \omega t}\right| \rightarrow 0$, $\left|B e^{k x+i \omega t}\right| \rightarrow \infty$. $\quad$ этом случ е из (3) будет следов ть $u \rightarrow \infty$, что противоречит условию

(2). тобы избеж ть этого противоречия - $B=0$.

$$
u=A e^{-k x+i \omega t}
$$

ОГД

$$
u(0, t)=A e^{i \omega t}, u_{x}(0, t)=-A k e^{i \omega t}, \dot{u}(0, t)=i \omega A e^{i \omega t} .
$$

одст вив соответствующие зн чения (8) во второе и третье ур внения системы (1), получим

$$
\left\{\begin{array}{l}
m_{1} \ddot{x}_{1}+\mu \dot{x}_{1}+\lambda x_{1}=A(\lambda+i \omega \mu) e^{i \omega t}, \\
m_{2} A \omega^{2} e^{i \omega t}=E S A k e^{i \omega t}+P e^{i \omega t}+\lambda\left(A e^{i \omega t}-x_{1}\right)+\mu\left(i \omega A e^{i \omega t}-x_{1}\right) .
\end{array}\right.
$$

ервое ур внение имеет общее решение

$$
x_{1}=e^{-\frac{\mu}{2 m_{1}} t}\left(C_{1} e^{\frac{\sqrt{\mu^{2}-4 m_{1} \lambda}}{2 m_{1}} t}+C_{2} e^{-\frac{\sqrt{\mu^{2}-4 m_{1} \lambda}}{2 m_{1}} t}\right)+\frac{\lambda+i \omega \mu}{\lambda+i \omega \mu-m_{1} \omega^{2}} A e^{i \omega t}
$$

ри $t \rightarrow \infty$ первый член стремится к нулю. оэтому уст новившиеся колеб ния демпфирующего груз описыв ются вторым членом

$$
x_{1}=\frac{\lambda+i \omega \mu}{\lambda+i \omega \mu-m_{1} \omega^{2}} A e^{i \omega t} .
$$

одст новк этого зн чения во второе ур внение системы (9) приводит к р венству

$$
A\left[\left(m_{2} \omega^{2}-E S k\right)\left(\lambda+i \omega \mu-m_{1} \omega^{2}\right)+m_{1} \omega^{2}(\lambda+i \omega \mu)\right]=P\left(\lambda+i \omega \mu-m_{1} \omega^{2}\right) .
$$

тсюд

$$
A=\frac{P\left(\lambda+i \omega \mu-m_{1} \omega^{2}\right)}{\left(m_{2} \omega^{2}-E S k\right)\left(\lambda+i \omega \mu-m_{1} \omega^{2}\right)+m_{1} \omega^{2}(\lambda+i \omega \mu)} .
$$

ри $m_{1}=0$ будем иметь

$$
A=\frac{P}{m_{2} \omega^{2}-E S k} \text {. }
$$

к и следов ло ожид ть, при отсутствии демпфирующего устройств мплитуд колеб ний уст новки не з висит от п р метров $\lambda$ и $\mu$.

одст вим (11) в (10), получим

$$
x_{1}=\frac{\lambda+i \omega \mu}{\left(m_{2} \omega^{2}-E S k\right)\left(\lambda+i \omega \mu-m_{1} \omega^{2}\right)+m_{1} \omega^{2}(\lambda+i \omega \mu)} P e^{i \omega t} .
$$

К К К уст новк и вместе с ней нижний конец колонны с течением времени должны прийти в неподвижность, то при всех дост точно больших $t$ мплитуд коле- 
б ний должн быть р вн нулю: $A=0$. то условие будет выполняться, если пр в я ч сть (11) р вн нулю:

$$
\lambda+i \omega \mu-m_{1} \omega^{2}=0
$$

тсюд н ходим условия неподвижности уст новки

$$
\lambda=m_{1} \omega^{2}, \mu=0 .
$$

одст вив (14) в (13), получим з висимость смещения груз от времени

$$
x_{1}=\frac{P}{m_{1} \omega^{2}} e^{i \omega t} .
$$

т к, при выполнении условия мплитуд колеб ний уст новки р вн нулю. сли же условия (15) не выполняются, то модуль мплитуды колеб ний (его мы обозн чим той же буквой $A)$ будет р вен

$$
\begin{gathered}
A=P\left[\left(\lambda-m_{1} \omega^{2}\right)^{2}+(\omega \mu)^{2}\right]^{1 / 2} \cdot\left\{\left[\left(m_{2} \omega^{2}-E S H\right)\left(\lambda-m_{1} \omega^{2}\right)+E S G \omega \mu+\lambda m_{1} \omega^{2}\right]^{2}+\right. \\
\left.+\left[\omega \mu\left(m_{1} \omega^{2}+m_{2} \omega^{2}-E S H\right)-E S G\left(\lambda-m_{1} \omega^{2}\right)\right]^{2}\right\}^{-1 / 2} .
\end{gathered}
$$

то выр жение получ ется из (12) после з мены $k$ комплексным зн чением (6).

риведем пример исследов ния того, к к ведет себя вблизи зн чений (15) мплитуд $A(\lambda, \mu)$, определяем я формулой (16). ля этого р ссмотрим колонну с п р метр ми

$$
E S=89710^{6} \mathrm{H}, \quad=10^{4} \quad, m_{l}=500 \mathrm{Kr}, m_{2}=1000 \mathrm{Kг}, \quad=5160 \mathrm{M} \mathrm{c}^{-1}, b=3 \mathrm{c}^{-1} .
$$

усть $\mathrm{n}=50$ об $\mathrm{c}^{-1}$ и $\omega=2 \pi n=314,16 \mathrm{p}$ д $\mathrm{c}^{-1}$. рис. 2 пок 3 н $з$ висимость мплитуды от $\lambda$ при $\mu=0$.

ис. 2. висимость мплитуды от $\lambda$ при $\mu=0$.

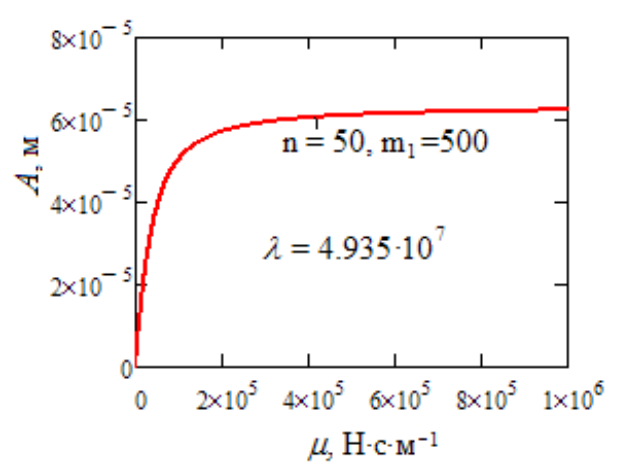

ля ср внения д н линия мплитуды колеб ний устройств при условии, что демпфирующий груз отсутствует, то есть при $m_{1}=0$. pис. 3 приведен 3 висимость мплитуды от $\mu$ при $\lambda=m_{1} \omega^{2}=4,93510^{7} \quad \mathrm{M}^{-1}$.

ис. 3. висимость мплитуды от $\mu$ при $\lambda=m_{1} \omega^{2}=4,93510^{7} \quad \mathrm{M}^{-1}$. 
з (16) следует, что к к при $\lambda \rightarrow \infty$, т к и при $\mu \rightarrow \infty$ мплитуд выходит н одно и то же пл то

$$
A \rightarrow \frac{P}{\sqrt{\left[\left(m_{1}+m_{2}\right) \omega^{2}-E S H\right]^{2}+(E S G)^{2}}} .
$$

рис. 4 пок з н совместн я з висимость мплитуды от $\lambda$ и $\mu$ в тех же ди п зон х их изменения.

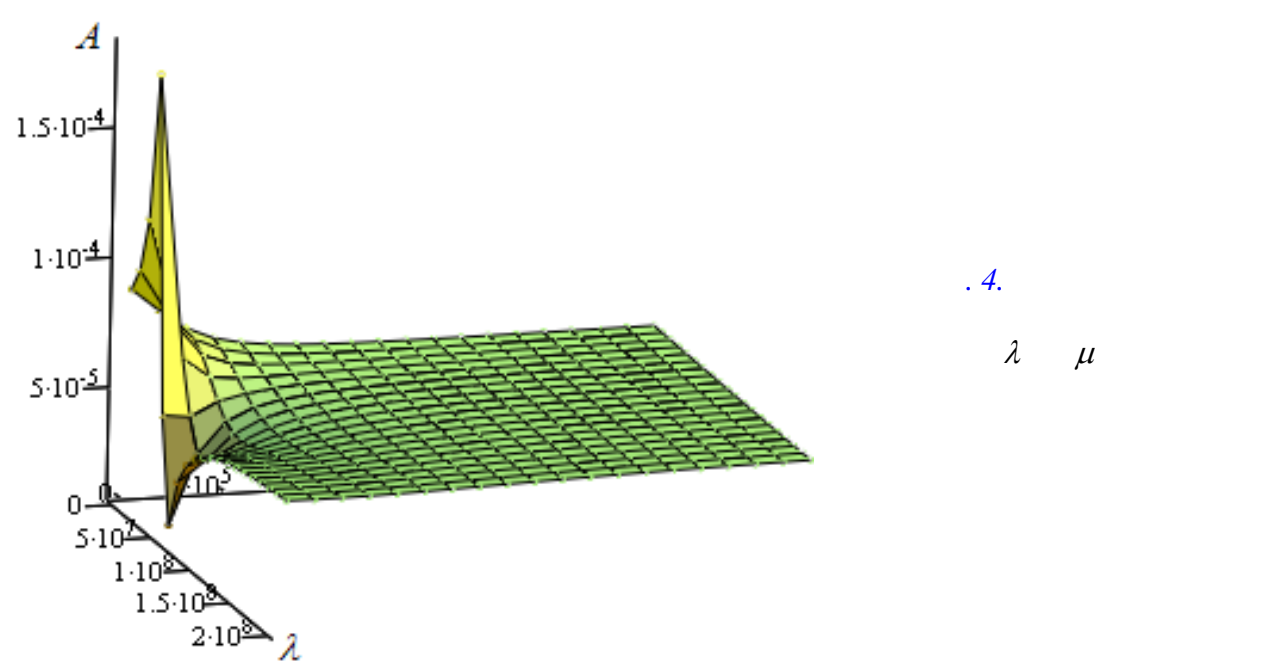

рис. 5 приведены гр фики мплитуды при $n$, р вном 44, 46 и 48 об $\mathrm{c}^{-1}$. рис. 5 гр фики построены при $\mu=0$, н рис. $5 \sigma-$ при $\lambda=m_{1} \omega^{2}$, где в обоих случ ях $\omega=2 \pi n$.
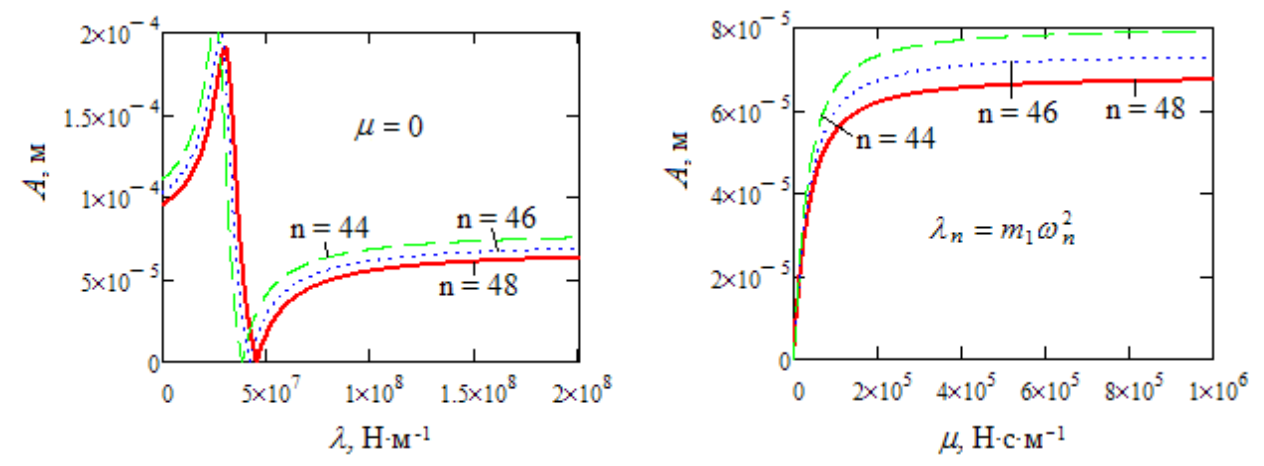

6

ис. 5. р фики мплитуды при $n$, р вном 44, 46 и 48 об $c^{-1}$. :

$$
-\mu=0 ; \sigma-\lambda=m_{1} \omega^{2}
$$

т к, если уст новк электроцентробежного н сос сн бжен демпфирующим устройством, п р метры $\lambda$ и $\mu$ которого н ходятся вблизи зн чений (15), то предст вляется возможным существенно снизить мплитуду колеб ний уст новки, что бл гоприятно ск жется н длительности ее эксплу т ции.

писок литер туры

1. ин мик бурильного инструмент при проводке вертик льных, н клонных и горизонт льных скв жин / бдр химов, . . леев, . . узин, . . улейм нов. - б.: « едр », 2011. -244 с. 


\section{ведения об втор $x$}

бдр химов

влитзян

бирвянович

д. т. н., профессор, з ведующий к федры «еф тепромысловые м шины и оборудов ние», фимский госуд рственный нефтяной технический университет, фили л, г. ктябрьский, тел. 8(34767)65401,e-mail: npmo@mail.ru

леев хметс лим бирович, д. профессор $\quad$ федры «ефтег зовое оборудов ние», льметьевский госуд рственный нефтяной институт, 2. льметьевск, тел. 8(8553)310124, e-mail: agni-ngo @mail.ru

икбул тов олия льдусовн, к. доцент к федры «ефтег зовое оборудов ние», льметьевский госуд рственный нефтяной институт, 2. льметьевск, тел. 8(8553)310124, e-mail: agni-ngo @mail.ru

бнов ергей еонидович, ссистент $\kappa$ федры «ефтег зовое оборудов ние льметьевский госуд рственный нефтяной институт, г. льметьевск, тел. 8(8553)310124, e-mail: agni-ngo@mail.ru

хриев ристин ин товн, препод в тель к федры "ефтепромысловые м шины и оборудов ние», фимский госуд рственный нефтяной технический университет, фили л, г. $к-$ тябрьский, тел. 8(34767)65401, e-mail: npmo@mail.ru
Information about the authors

Gabdrakhimov M. S., Doctor of Engineering, professor, head of the chair "Oilfield machines and equipment», Ufa State Petroleum Technical University affiliate in the town of Oktyabrski, phone: 8(34767)65401,e-mail: npmo@mail.ru

Galeev A. S., Doctor of Engineering, professor of the chair "Oil and gas production equipment», Almetievsk State Petroleum Institute, phone: 8(8553)310124, e-mail: agni-ngo@mail.ru

Bikbulatova G. I., Candidate of Science in Engineering, associate professor of the chair "Oil and gas production equipment», Almetievsk State Petroleum Institute, phone: 8(8553)310124, e-mail: agni-ngo@mail.ru

Sabanov S. L., assistant of the chair "Oil and gas production equipment», Almetievsk State Petroleum Institute, phone: 8(8553)310124, e-mail: agni-ngo@mail.ru

Fakhrieva $\boldsymbol{K} . \boldsymbol{R}$., lecturer of the chair "Oilfield machines and equipment», Ufa State Petroleum Technical University affiliate in the town of $O \mathrm{k}$ tyabrsk, phone: 8(34767)65401, e-mail: npmo@mail.ru 